\title{
Clinical analysis on the therapeutic effect of reduning injection in acute upper respiratory infection.
}

\author{
Gui-Yu Zhang ${ }^{1}$, Dong-Mei Guo ${ }^{2 *}$, Wei-Rong Liu ${ }^{3}$, Zhi-Yong Zhang ${ }^{4}$ \\ ${ }^{1}$ Department of Infectious Diseases, Tangshan Gongren Hospital, Tangshan, Hebei, PR China \\ ${ }^{2}$ Department of Pediatrics, Tangshan Gongren Hospital, Tangshan, Hebei, PR China \\ ${ }^{3} \mathrm{ICU}$, Tangshan Gongren Hospital, Tangshan, Hebei, PR China \\ ${ }^{4}$ Department of Pathology, Tangshan Gongren Hospital, Tangshan, Hebei, PR China
}

\begin{abstract}
Objective: This study aims to investigate the clinical value of reduning injection in treating acute upper respiratory infection.

Methods: A total of 72 patients with acute upper respiratory infection in our hospital from March 2015 to February 2017 were selected and divided into the control and observation groups randomly by the odd-even method. The control group (36 cases) was treated by ribavirin injection, whereas the observation group (36 cases) was treated by reduning injection. The effect of clinical therapies, improvement of symptoms, normal proportions of White Blood Cells (WBCs) and neutrophils, and statistical results of occurrence rate of untoward effect between the two groups were compared.

Results: The observation group presents significantly higher therapeutic effect $(\mathbf{9 7 . 2 2} \%)$ than that in the control group $(\mathbf{5 8 . 3 3 \%})(\mathbf{P}<\mathbf{0 . 0 5})$. The improvement time of symptoms in the observation group is shortened significantly compared with that in the control group $(\mathbf{P}<0.05)$. The observation group shows dramatically higher proportions of WBCs and neutrophils than those in the control group $(P<0.05)$. The occurrence rate of untoward effect in the observation group is $\mathbf{2 . 7 8 \%}$, which is reduced dramatically compared with that in the control group $(22.22 \%)(\mathbf{P}<0.05)$.

Conclusions: Reasonable reduning injection in clinical treatment of acute upper respiratory infection can guarantee improvement in therapeutic effect, shortening in improvement time of symptoms, growth in proportions of WBCs and neutrophils, and reduction in untoward effect. This approach can optimize prognosis of patients with acute upper respiratory infection.
\end{abstract}

Keywords: Acute upper respiratory infection, Reduning injection, Clinical analysis.

Accepted on December 5, 2017

\section{Introduction}

Acute upper respiratory infection is a disease with relatively high clinical occurrence rates. Its symptoms mainly involve cough, fever, and headache [1]. It may inflict people at any time.

Acute upper respiratory infection not only threatens the physical health of patients but also increases the occurrence rate of serious complications [2,3]. Thus, early clinical therapy to acute upper respiratory infection can reduce pains of patients significantly.

This study aims to explore effective therapies to acute upper respiratory infection and interpret the clinical application value of reduning injection.

\section{Information and Methods}

\section{General information}

A total of 72 patients with acute upper respiratory infection in our hospital from March 2015 to February 2017 were selected and divided into the control and observation groups randomly by the odd-even method. The control group (36 cases) included 21 males and 15 females who were aged from 15 to 76 with an average age of $34.29 \pm 7.52$. The onset time of stroke ranged from $2 \mathrm{~h}$ to $47 \mathrm{~h}$ with an average onset time of $25.17 \pm 5.22 \mathrm{~h}$. In this group, 19, 5, 10, and 2 cases of pharyngeal hyperaemia, herpangina, antiadoncus, and conjunctival injection, respectively, were observed. A total of 5, 22, and 9 cases showed reduced, normal, and increased proportions of White Blood Cells (WBCs), respectively. The observation group (36 cases) covered 23 males and 13 females who were aged from 16 to 79 with an average age of $34.31 \pm 7.59$. The onset time of 
stroke ranged from $2 \mathrm{~h}$ to $49 \mathrm{~h}$ with an average onset time of $(25.23 \pm 5.29 \mathrm{~h})$. In this group, 21, 4, 9, and 2 cases of pharyngeal hyperaemia, herpangina, antiadoncus, and conjunctival injection, respectively, were found. A total of 4, 23, and 9 cases exhibited reduced, normal, and increased proportions of WBCs, respectively. The two groups had no significant difference in general information, such as gender, age, onset time of stroke, type of disease, and proportion of WBC $(\mathrm{P}>0.05)$.

\section{Selection and exclusion criteria}

Selection criteria: The clinical symptoms of all the patients, including dizziness, fever, nasal obstruction, nasal discharge, ophthalmodynia, and cough, met the relevant diagnosis standards of acute upper respiratory infection. Laboratory examination revealed that the patients were suffering from a series of symptoms, such as pharyngeal hyperaemia, conjunctival congestion, herpangina, and antiadoncus. After lung auscultation, no dry and moist rales were observed. Blood routine examination was performed to examine anomalies of WBCs [4].

Exclusion criteria: Patients with serious cerebral insufficiency, immune system disease, severe lung insufficiency, mental disease, and serious cardiac insufficiency were excluded.

\section{Methods}

The control group was treated by ribavirin injection, whereas the observation group was treated by reduning injection. Ribavirin injection for the control group was prepared by mixing $0.5 \mathrm{~g}$ of drugs and $250 \mathrm{ml}$ of $5 \%$ glucose solution [5]. Intravenous drip of ribavirin injection was administered to the patients once a day for five days. Reduning injection for the observation group was prepared by mixing $20 \mathrm{ml}$ of drugs and $250 \mathrm{ml}$ of $0.9 \%$ sodium chloride injection. Intravenous drip of reduning injection was given to patients once a day for five days.

\section{Judgment standard of therapeutic effect}

Cure: The patients showed normal proportion of total WBCs, significantly relieved series of symptoms of respiratory infection, and no abnormal body temperature and fever symptoms after the treatment. Improvement: The patients showed slight anomaly of total WBCs, relieved series of symptoms of respiratory infection, controlled fever, and certain reduction in body temperature after the treatment. Ineffectiveness: The patients still had abnormal total WBCs, failed to relieve series of symptoms of respiratory infection, and showed significantly abnormal body temperature and high fever [6].

\section{Statistical analysis}

The therapeutic outcomes of all the patients with acute upper respiratory infection were analysed by SPSS20.0. The enumeration data (e.g., proportions of neutrophils) of the two groups were expressed in $\%$ and examined by $\chi^{2}$-test. Measurement data (e.g., improvement time of symptoms) were expressed by $\overline{\mathrm{x}} \pm \mathrm{s}$ and examined by $\mathrm{t}$-test. $\mathrm{P}<0.05$ indicates statistically significant difference between the two groups.

\section{Results}

\section{Therapeutic effect}

The therapeutic effect in the observation group was $97.22 \%$, which was significantly higher than that in the control group $(58.33 \%)(\mathrm{P}<0.05)$. The results are shown in Table 1 .

\section{Improvement time of symptoms}

The observation group took significantly shorter time for the improvement of symptoms than did the control group $(\mathrm{P}<0.05)$. The results are shown in Table 2 .

\section{Proportions of WBCs and neutrophils}

The proportions of WBCs and neutrophils in the observation group were significantly higher than those in the control group $(\mathrm{P}<0.05)$. The results are shown in Table 3 .

\section{Untoward effect}

The occurrence rate of untoward effect in the observation group was $2.78 \%$, which was sharply reduced compared with that in the control group $(22.22 \%)(\mathrm{P}<0.05)$. The results are shown in Table 4.

Table 1. Comparison of therapeutic effect between two groups (cases).

\begin{tabular}{llllll}
\hline Groups & $\mathbf{n}$ & Cure & $\begin{array}{l}\text { Improvemen } \\
\mathbf{t}\end{array}$ & $\begin{array}{l}\text { Ineffectivene } \\
\text { ss }\end{array}$ & $\begin{array}{l}\text { Total } \\
\mathbf{( \% )}\end{array}$ \\
\hline $\begin{array}{l}\text { Observatio } \\
\text { n group }\end{array}$ & 36 & 24 & 11 & 1 & 97.22 \\
\hline $\begin{array}{l}\text { Control } \\
\text { group }\end{array}$ & 36 & 6 & 15 & 15 & 58.33 \\
\hline$X^{2}$ & & & & & 15.7500 \\
\hline$P$ & & & & $<0.05$ \\
\hline
\end{tabular}

Table 2. Comparison of improvement time of symptoms between two groups $(\bar{x} \pm s$, day $)$.

\begin{tabular}{lllllll}
\hline Groups & $\mathbf{n}$ & $\begin{array}{l}\text { Time for } \\
\text { relief from } \\
\text { coughing }\end{array}$ & $\begin{array}{l}\text { Time for } \\
\text { relief from } \\
\text { nasal } \\
\text { discharge }\end{array}$ & $\begin{array}{l}\text { Time for } \\
\text { relief from } \\
\text { fever }\end{array}$ & $\begin{array}{l}\text { Time for } \\
\text { relief from } \\
\text { pharyngea } \\
\text { I } \\
\text { congestio } \\
\mathbf{n}\end{array}$ \\
\hline $\begin{array}{l}\text { Observatio } \\
\mathrm{n}\end{array}$ & 36 & $2.87 \pm 0.53$ & $2.37 \pm 0.43$ & $2.17 \pm 0.23$ & $2.79 \pm 0.37$ \\
\hline Control & 36 & $5.22 \pm 1.25$ & $4.83 \pm 0.55$ & $4.17 \pm 0.29$ & $4.36 \pm 0.30$ \\
\hline $\mathrm{t}$ & & 10.3850 & 21.1418 & 32.4205 & 19.7757 \\
\hline
\end{tabular}




\begin{tabular}{lllll}
\hline $\mathrm{P}$ & $<0.05$ & $<0.05$ & $<0.05$ & $<0.05$ \\
\hline
\end{tabular}

Table 3. Comparison of proportions of WBCs and neutrophils between two groups ( $n(\%))$.

\begin{tabular}{|c|c|c|c|c|c|c|c|}
\hline \multirow[t]{2}{*}{ Groups } & \multirow[t]{2}{*}{$\mathbf{n}$} & \multicolumn{3}{|c|}{ Proportion of neutrophils } & \multicolumn{3}{|c|}{ Total WBCs } \\
\hline & & Reduced & Normal & Increased & Reduced & Normal & Increased \\
\hline Observation & 36 & $1(2.78)$ & $34(66.67)$ & $1(2.78)$ & $1(2.78)$ & $34(66.67)$ & $1(2.78)$ \\
\hline Control & 36 & $6(16.67)$ & $22(61.11)$ & $8(22.22)$ & $5(13.89)$ & $24(66.67)$ & $7(19.44)$ \\
\hline$x^{2}$ & & 3.9560 & 11.5714 & 6.2222 & 2.9091 & 8.8670 & 5.0625 \\
\hline$P$ & & $<0.05$ & $<0.05$ & $<0.05$ & $>0.05$ & $<0.05$ & $<0.05$ \\
\hline
\end{tabular}

Table 4. Comparison of occurrence rate of untoward effect between two groups (cases).

\begin{tabular}{lllllll}
\hline Groups & $\mathbf{n}$ & Diarrhea & $\begin{array}{l}\text { Skin } \\
\text { itch }\end{array}$ & Vomit & $\begin{array}{l}\text { Skin } \\
\text { rash }\end{array}$ & $\begin{array}{l}\text { Total } \\
\text { occurrence } \\
\text { rate (\%) }\end{array}$ \\
\hline $\begin{array}{l}\text { Observatio } \\
\mathrm{n}\end{array}$ & 36 & 0 & 0 & 1 & 0 & 2.78 \\
\hline Control & 36 & 2 & 2 & 2 & 2 & 22.22 \\
\hline $\mathrm{X}^{2}$ & & & & & & 6.2222 \\
\hline $\mathrm{P}$ & & & & & $<0.05$ \\
\hline
\end{tabular}

\section{Discussion}

Acute upper respiratory infection is a disease with significantly high morbidity and threatens the physical and psychological health of patients [7]. According to etiological analysis, the incidence of acute upper respiratory infection of patients is highly correlated with virus infection. Acute upper respiratory infection requires close clinical attention and early specific treatment to reduce untoward effects significantly and thus prevent serious interference in patients' lives and activities [8].

Reduning injection achieves outstanding therapeutic effect on acute upper respiratory infection. According to ingredient analysis, reduning injection mainly consists of Lonicera japonica, Artemisia apiacea, and Fructus gardenia, A. apiacea presents the effect of dieresis and heat removal to cool blood [9]. L. japonica can clear away heat and toxic materials and dispel wind and heat. F. gardenia can clear heat, promote dieresis, remove pathogenic heat from the blood and toxic materials from the body, urge intense heat, and relieve restlessness. These components assure the full use of reduning injection and offer strong virus resistance and sterilizing effect, thereby easing headache and fever symptoms [10]. Consequently, the immunity of patients can be strengthened.

In this study, the observation group achieved remarkably higher therapeutic effect $(97.22 \%)$ than that in the control group $(58.33 \%)(\mathrm{P}<0.05)$. The improvement time of symptoms in the observation group is shortened significantly compared with that in the control group $(\mathrm{P}<0.05)$. The observation group shows dramatically higher proportions of WBCs and neutrophils than those in the control group $(\mathrm{P}<0.05)$. The occurrence rate of untoward effect in the observation group is $2.78 \%$, which is reduced dramatically compared with that in the control group $(22.22 \%) \quad(\mathrm{P}<0.05)$. These results demonstrate the high clinical value of reduning injection in treating acute upper respiratory infection.

\section{Conclusion}

In summary, reasonable reduning injection in clinical treatment of acute upper respiratory infection can significantly promote improvement in therapeutic effect, shortening in improvement time of symptoms, growth in proportions of WBCs and neutrophils, and reduction in untoward effect. This approach can optimize prognosis of patients with acute upper respiratory infection.

\section{References}

Moesker FM, Kampen JJA, Rossum AMC, Hoog M, Koopmans MPG, Osterhaus ADME, Fraaij PLA. Viruses as sole causative agents of severe acute respiratory tract infections in children. PLoS One 2016; 11: 0150776.

Udhaya STS, Rangarajan P. Brain tumour detection using discrete wavelet transform based medical image fusion. Biomed Res India 2017; 28: 684-688.

Zhou L, Zheng S, Xiao Q, Ren L, Xie X, Luo J, Wang L, Huang A, Liu W, Liu E. Single detection of human bocavirus 1 with a high viral load in severe respiratory tract infections in previously healthy children. BMC Infect Dis 2014; 14: 424.

Tromp I, Jong JK, Raat H, Jaddoe V, Franco O, Hofman A, Jongste J, Moll H. Breastfeeding and the risk of respiratory tract infections after infancy: The Generation R Study. PLoS One 2017; 12: 0172763.

Zou J, Zhou L, Zhou X, Wu X, Luo L, Luo Y, Tian J. The analgesic effect, acute toxicity, and influence on central nervous system of the new formula ketoprofen injection prepared by sodium acetate as hydrotropic agent. Lat Am J Pharm 2017; 36: 1361-1370.

Akben SB. Low-cost and easy-to-use grasp classification, using a simple 2-channel surface electromyography (sEMG). Biomed Res India 2017; 28: 577-582. 
Kim KY, Han SY, Kim HS, Cheong HM, Kim SS, Kim DS. Human coronavirus in the 2014 winter season as a cause of lower respiratory tract infection. Yonsei Med J 2017; 58: 174-179.

Chen J, Sun S, Xu Y, Fu X. Donepezil protects against glycerol-induced acute renal failure in rat. Lat Am J Pharm 2017; 36: 987-992.

Lappin MR, Blondeau J, Boothe D, Breitschwerdt EB, Guardabassi L, Lloyd DH, Papich MG, Rankin SC, Sykes JE, Turnidge J, Weese JS. Antimicrobial use guidelines for treatment of respiratory tract disease in dogs and cats: antimicrobial guidelines working group of the international society for companion animal infectious diseases. J Vet Intern Med 2017; 31: 279-294.
Linder JA, Singer DE. Health-related quality of life of adults with upper respiratory tract infections. J Gen Intern Med 2003; 18: 802-807.

\section{*Correspondence to}

Dong-Mei Guo

Department of Pediatrics

Tangshan Gongren Hospital

PR China 